\title{
The Meanings of Practices for Energy Consumption - a Comparison of Homes and Workplaces
}

\author{
Jenny Palm and Sarah J Darby
}

\begin{abstract}
We examine how building and appliance technologies relate to their use by occupants through practices at home and at work. The aim is to analyse how practices are influenced by buildings and other technologies and by social requirements and to add to ongoing research on how to contribute to a transition to more sustainable everyday practices. Interview, quantitative and observational material are used to compare experiences of occupying and using two different types of buildings, passive housing and large modern research laboratories. We apply the practice theory approach. The passive house case showed that the main project of a liveable, low-impact new building was on a fairly manageable scale, with a viable design and occupants who were prepared to adapt to it. The research lab study showed, however, that the configuration of unsustainable technologies and practices can occur at the design stage, and that most actors had very limited room for manoeuvre.
\end{abstract}

Keywords: practice theory, low-energy building, tenants

\section{Introduction}

Recent years have seen increased interest in ameliorating global warming, and considerable attention has been paid to energy-related emissions. The EU Directive $2012 / 27$ states that, by the year 2020, EU member states should improve their energy efficiency by $20 \%$ compared with businessas-usual projections. This applies to all end users, and is to be achieved through measures in all sectors. In the EU, the building sector accounts for approximately $40 \%$ of total energy demand. This is one reason why we see increased interest in energy-efficient buildings, and in practices that reduce the demand for fuel and electricity.

A building's design always includes an idea on how the building will be used, according to Gieryn (2002). These kinds of ideas are not necessarily conscious but embedded in norms and social structures. Yet they still have consequences for the occupants of the building. From a sociotechnical perspective, researchers have long emphasized that the ways in which a building is used have great impact on its energy performance (Wilson \& Dowlatabadi, 2007; Moezzi \& Lutzenhiser, 2010; Gram-Hanssen, 2010). Studies have also shown that users have greater impact 
on energy consumption than designers and constructors usually estimate (Pett \& Guertler, 2004; Steemers \& Yun, 2009). In order for our understanding of energy use in buildings to increase, we need to go beyond simplistic references to unpredictable 'user behaviour' to explain weak energy performance (e.g. Gill et al., 2010). Social studies of science and technology have also shown different interpretations and uses of design to be possible, and that intentions and political ideas can be built into design (Stewart \& Williams, 2005). Early work on this perspective traced ideas built into technology by designers and producers (Glad, 2012) and, more recently, social learning related to the use of different energy technologies has been acknowledged (e.g. Darby, 2006; Rohracher, 2006; Stagl, 2006; Vergragt \& Szejnwald Brown, 2006). Designers and users of modern technology need to think about the contexts in which technology will be used, even if everyday life use offers endless variations. Sørensen (1996) has emphasised that technologies of everyday life form heterogeneous networks of technology hardware, software and the social systems of routines and culture. Shove (2003) has stressed the importance of studying normal practices, since much of our resource consumption is embedded in everyday life activities, habits and routines.

More research is needed regarding the actual use of energy efficient buildings, and the ways in which low-energy-demand practices can be developed in an everyday context at home and at work. Not so much research has been conducted on this, and too often it is more or less taken for granted that, for example, technological provisions alone will reduce energy use and greenhouse gas emissions. In this article we will focus on energy use in passive houses and research labs designed for 24-hour use, using practice theory as our analytical framework. The passive house concept is described in more detail below, but the idea is to minimize heating needs by creating an air-tight building envelope and to gain "passively" the heat from the sun, the tenants themselves, and the equipment installed in the house. The four research labs were designed to be used as 24-hour buildings and were built at a time when the university responsible for them had adopted a target to reduce carbon emissions by $20 \%$. The buildings were designed with slightly different technical approaches to heating, cooling and ventilation, as outlined below, but with a very similar approach to function and management.

Practice theoryhas been increasinglyused in relation to domestic energy consumption over the past decade (Gram-Hanssen, 2010; Wilhite, 2008) but rarely applied to energy use in non-domestic buildings. We reflect on energy-related practices in both homes and workplaces, in order to discuss similarities and differences and to find out if a multi-sited methodology approach can shed new light on practice theory and contribute to new lines of questioning. The practice theory framework will be used to examine the implementation of passive housing in Linköping, Sweden and 24-hour research labs in Oxford, UK. Since both passive houses and 24-hour research labs are innovative design approaches, we can expect that they will challenge occupants' practices and that these contrasting case studies are highly suitable for assessing how unfamiliar technology influences practices. The homes and workplaces under discussion are in different countries, but they reflect developments in building design and user practices that may be seen in cool temperate climates generally. As most adults in industrialised countries routinely move between the home and the workplace, adopting what they see as appropriate practices for each, it seems reasonable to consider them together: "the 
multi-sited approach feels necessary in many circumstances as a faithful reflection of lives lived not in discrete locations, but through various forms of circulation and connection" (Hine, 2007: 656).

Material factors contribute to, and set limits on, the potential to reduce energy use in a building, and the design of new buildings will have consequences for occupants' energy patterns for decades to come. Our research casts some light on how user practices relate to the fabric of a building and the technologies inside it. The aims are to apply practice theoretical concepts to buildings that have been specially designed to be innovative, and to analyse in general terms how practice theory can be used to improve the understanding of energy use in buildings and contribute to demand reduction in homes and workplaces.

\section{Theoretical Framework: Practices Influencing Energy Use}

People in their everyday domestic lives are engaged in practices such as cooking, eating, sleeping, shopping and dancing. Also work includes a wide variety of practices. When people are asked about their everyday life, they usually describe the practices they are engaged in (Røpke, 2009).

While the roots of practice theory can be traced back to the Enlightenment, the term itself has more recent origins. One branch of practice theory that has been developed within sociology (our main frame of reference) emanates from Bourdieu (1977) and Giddens (1984), and has been developed further by Schatzki (1996) and Reckwitz (2002). In relation to energy consumption, Shove (2003) and Gram-Hanssen (2010) have made important contributions. However, practice theory is not yet a commonly-agreed theory, and a practice is a dynamic concept. A very general understanding of the concept would be that a practice is a behaviour "in which bodies are moved, objects are handled, subjects are treated, things are described and the world is understood" (Reckwitz, 2002: 250). Practice theory aims to focus on the importance of physical, social and regulatory contexts, meanings, and human action. Context includes systems of provision and available technologies, while human action encompasses behaviour and choice (Spaargaren, 2003). The idea is to study everyday practices not only from a psychological, behavioural or technological perspective, but to look at activities in their social contexts, including for example the constant negotiation with time constraints, financial resources and the needs of others. It is to put the things we do in our everyday life in the perspective of cultural and social networks.

Practice theory is also based on the idea that in the performance of everyday life it is possible to identify clusters of activities, whose coordination and interdependence make it meaningful for practitioners to conceive of them as entities: for example cooking, cleaning and accounting. An organized set of activities is seen as a coordinated entity, or 'cluster', when it is recognizable across time and space. A practice is a relatively enduring entity (Shove et al., 2007). A practice is also a set of doings and sayings: Schatzki describes how a collection of sayings and doings forms a level of tasks, which in turn may form a level of projects. Practices are social, and by performing a practice we connect not only with those we interact with directly but also with all other people performing the practice (Gram-Hanssen, 2010).

Activities are guided by practical intelligibility: what it makes sense for individuals to do. This is what guides practices, and the reasons for performing a practice in a certain way can be based on 'correct' (formal) knowledge or can 
have totally different grounds, sometimes referred to as tacit or informal knowledge. People simply perform their practices in a way that makes sense for them.

Practices are also an expression of the distributed agency of people and things. A practice usually involves the use of various materials and technologies, although people are not necessarily aware of all the resources that are involved. The 'invisibility' of energy use, in particular, has often been noted (e.g. Jensen \& Gram-Hanssen, 2008; Löfström \& Palm, 2011; Palm \& Ellegård, 2011).

In our view, elements of practice directly affect end-use efficiency, life-cycle efficiency and environmental impact, and the analysis of practices offers a promising tool for understanding how best to improve these. For the analysis of how building design and structure influences energyrelated practices in our case studies, we will adopt the framework developed by Gram-Hanssen (2010: 2011), who provides a very useful summary of the issues raised above and interprets practices in terms of technologies, routines, knowledge, and meaning. In this framework, technologies are products or things important for structuring practices. Routines are embodied habits and know-how, i.e. knowing what to do and how to react in a situation. Routines include bodily and mental activities carried out by practitioners when they both respond and contribute to sustaining and developing a practice. Knowledge includes rules of how to do things and technical knowledge. In some interpretations (including this one), it also includes cultural myths of energy consumption. Meanings accumulate through engaged practitioners and are an important element of holding a practice together (Gram-Hanssen, 2011).

Next, we will focus on how technology and systems of provision shape everyday energy use in homes and in a type of energy- intensive workplace. We compare energyrelated practice in each, and discuss how the buildings where people live or work restrict or enable practices that contribute to improved energy efficiency and demand reduction. From this, we can draw out some implications for understanding practices in the context outlined above.

\section{The Case Studies - Background and Research Methods}

Multi-sited ethnography is an established research method among anthropologists and sociologists. Marcus states in his article from 1995 that multi-sited ethnography defines its object as the study of social phenomena that cannot be accounted for by focusing on a single site. The idea is to combine multi-sited work with the need for in-depth analysis (Falzon, 2009). So far, research applying practice theory to energy use has been single-sited in the sense that either energy related everyday practices at home have been in focus or energy related practices at work. There has been a lack of analysis where different sites have been included. The idea in this article is to do that. We will compare energy-related practices in domestic buildings with non-domestic buildings in order to see how such an approach can contribute to energy research using a sociologically-inspired practice theory approach.

This choice of such seemingly disparate building types may seem odd at first, yet it can be a basis for showing how practice theory applies across domains that are traditionally kept separate. (For example, the research literature contains far more material on residential energy use than on energy use in non-domestic buildings, while there is very little research that addresses both and seeks out commonalities and differences.) Le Corbusier, in his 1923 book 'Vers une Architecture', famously spoke of a 
house as a machine for living in. This may sit uncomfortably with our ideas of domesticity. However, it perhaps becomes more accessible after considering a laboratory as a machine for carrying out research in; and even more so if both laboratories and houses are the products of highlyspecialised design techniques. Pollock and Williams (2010) have argued persuasively that single-site and short-term studies can seriously limit what we are able to learn about the evolution of e-infrastructure. We show here how a multi-site approach sheds light on possible developments in energy infrastructure, in a more comprehensive way than if we had stayed within the usual domestic/non-domestic boundaries.

Once we start thinking about buildings as for practices, as well as being the product of practices and maintained by practices, we are on the way to a broader understanding of what happens in buildings and how it can change. (In doing so, incidentally, we find that the concept of energy efficiency can be unhelpfully narrow. Energy efficiency is usually understood as a ratio of the energy used for a particular 'service' to the energy input delivered for that service. ${ }^{1}$ But, as we see in passive-standard housing, the service of warmth is mostly not supplied by kWh of gas or electricity delivered specifically for heating. Most of the warmth comes from the nature of the building itself and the activity of the people within it. Moreover, the activity is related to the occupants' knowledge of how best to achieve thermal comfort. The technical breakthrough of the passive house can therefore be seen primarily as the introduction of a set of new practices rather than as an efficiency improvement.)

One case study concerns buildings in Oxford, UK, occupied by several hundred people at peak times. (The empirical material is taken from Darby et al. (2010) except where otherwise indicated.) These buildings serve as an environment for scientific research in the higher education sector but are, like housing, places where the comfort and convenience of occupants are important. The buildings also form part of a system of accountability, though. In response to governmental goals for carbon emissions reduction, the University of Oxford had adopted a target of $20 \%$ reduction by 2010 over 1990 levels, singled out as "precise and ambitious" (Fawcett, 2005). However, that reduction was not actually achieved, as emissions per square meter rose by $15 \%$ from 124 to $143 \mathrm{~kg} \mathrm{CO}$ over this period. In the light of the evidence we gathered for this study, this is not surprising: the biggest energy consumers in the higher education sector, and those with the fastest growth in consumption, are the research-intensive universities. Moreover, university buildings used "out of hours" (between $7 \mathrm{pm}$ and $7 \mathrm{am}$ on weekdays, at weekends and during public holidays) rank amongst the highest energy users of all.

The researchers gathered data on overnight usage of four recently-built 24-hour research labs at Oxford (one of which accounted for over $6 \%$ of the university's energy use). They also looked at occupancy and at the ways in which the buildings fulfilled their intended function. Information came from meter data, floor plans, interviews, occupant surveys, and observation. Interviews were undertaken with security personnel, building managers, administrators, lab managers, lab technicians and researchers. Two primary interviews were conducted with each of the four building managers, at the beginning and end of the data-gathering, which lasted altogether about a month. This approach was followed in order to assess the "status quo" of energy management, and to discuss findings with the four people who were most familiar with their operation of "their" buildings. The surveys nearly all come from members of single research teams in each 
building, $(\mathrm{n}=38,38,19$ and 14). These were carried out in order to gain an indication of researcher views that could complement the quantitative data. All the labs were observed overnight as well as during the day. This allowed the researchers to complement "swipe card" data on comings and goings, to see how much lighting and equipment were in use at night and to talk with night-time users and night watchmen.

The second case concerns a block of semi-detached passive apartments in the municipality of Linköping in Östergötland, South Central Sweden. The municipally owned housing company, $\mathrm{AB}$ Stångåstaden, built nine apartments according to the Swedish passive house standards in the suburb of Lambohov. Two types of apartments were built: singlefloor apartments with three rooms $\left(73 \mathrm{~m}^{2}\right)$ and two-floor apartments with four rooms $\left(105 \mathrm{~m}^{2}\right)$. The four-room apartments have a shower room on the ground floor and a bathroom on the first floor.The ground floor also contains a laundry room with a washing machine, tumble dryer, and central heating unit. The three-room apartments have a combined bathroom and laundry room that includes the central heating unit.

The researchers measured indoor temperatures, and interviewed representatives of the housing company Stångåstaden and tenants living in the apartments. At Stångåstaden, we interviewed the environmental manager, the project manager for the buildings in Lambohov, two "sellers" who showed the apartments to prospective tenants, the area officer in charge until the autumn of 2009, and the new area officer who started work in the autumn of 2009. We also interviewed one or both adults living in seven of the nine passive house-concept apartments. These tenants were interviewed three times, first when they moved into the apartment (February-March 2009), then after their first summer (September-October 2009), and the last time after their first winter (MarchApril 2010). In this way, we were able to track what they had learned about living in their new homes over a period of just over a year.

We have re-analyzed our empirical data with a focus on how energy-related practices were performed and described by the informants, and also in relation to the chosen theoretical framework. Below, we have divided the sections according to our framework, i.e. how practices are influenced by technology, meanings, knowledge and routines. This is of course an analytical construction and not a reflection of a practice, because practices are performed in relation to all of these.

\section{Technologies Structuring Practices}

We will start by focusing on technologies. As discussed in the theory section above, technologies are products or physical things influencing a practice.

\section{The Research Labs}

The UK case study examined four buildings (B, C, G, and O). Building B used mixedmode ventilation with a naturally-ventilated atrium. However the other three used mechanical ventilation only and were, effectively, sealed boxes apart from the doorways. (Several respondents expressed frustration at their perceived lack of control over their working conditions - a common feature of buildings with centralised building management systems, few on/ off switches, and windows that cannot be opened.)

$\mathrm{G}$ was the smallest building, the only one without an atrium, and had a relatively low base: peak load ratio for electricity usage that is, there was markedly less electricity consumption at night and over weekends and holidays than during normal working 
hours. This reflected the relatively low contribution of air-conditioning to the total load.

Humidifiers had been installed in the two newest buildings, but they were switched off after a few months because of the huge expense of running them. It is hard to understand why it was ever thought necessary to supply humidifiers to buildings in the (humid, cool-temperate) Thames Valley. This decision could be seen as an example of influence from other climates and building standards.

The management of research equipment was also an important factor in determining consumption. For example, fume cupboards require constant ventilation and make large demands, but the energy used is minimised if they are kept $90 \%$ shut while not in use. Building managers were keen to persuade researchers to shut the fume cupboard doors whenever possible. Refrigerating samples at $-80^{\circ} \mathrm{C}$ posed a problem in one building, as the number of low-temperature fridges increased and the waste heat from them had to be countered by additional airconditioning.

Table 1 shows some descriptive statistics on gas and energy use, and also the magnitude of baseload power demand $(\mathrm{kW})$ for these buildings, which is particularly striking: this is the demand for HVAC (heating, ventilation, and air-conditioning), lighting and equipment at its lowest, when the building has few or no people in it. The ratio of electrical baseload to peak load (when researchers, technicians, and administrators were going about their work) was roughly $75 \%$ for building $\mathrm{B}$, while the lowest ratio recorded was around $40 \%$, for $\mathrm{G}$. These figures partly reflect the ways in which the functions of the building continue even when there is no-one there: experimental samples are kept chilled, warmed, or agitated, and IT equipment continues to operate. But they also reflect consumption that is related to the possibility that people are in the buildings, in particular heating, cooling, ventilation, and lighting.

Table 1. Annual gas and electricity consumption and internal area, with approximate electricity base load. ${ }^{2}$

\begin{tabular}{|l|c|c|c|c|c|}
\hline Building & $\begin{array}{c}\mathrm{G} \text { Gas } \\
\mathrm{kWh} / \mathrm{m}^{2}\end{array}$ & $\begin{array}{c}\text { Electricity } \\
\mathrm{kWh} / \mathrm{m}^{2}\end{array}$ & $\begin{array}{c}\text { Gas/ } \\
\text { occupant } \\
\text { (kWh/yr) }\end{array}$ & $\begin{array}{c}\text { Electricity } \\
\text { / occupant } \\
\text { (kWh/yr) }\end{array}$ & $\begin{array}{c}\text { Approx. } \\
\text { electric } \\
\text { baseload } \\
(\mathrm{kW})\end{array}$ \\
\hline $\mathrm{B}$ & 194 & 395 & 7,842 & 15,992 & 500 \\
\hline $\mathrm{C}$ & 395 & 379 & 11,618 & 11,144 & 600 \\
\hline $\mathrm{G}$ & 244 & 273 & 3,525 & 3,946 & 60 \\
\hline O & 334 & 480 & 11,215 & 16,130 & 600 \\
\hline $\begin{array}{l}\text { CIBSE } \\
\text { for 'typical' science lab }\end{array}$ & 132 & 175 & & & \\
\hline $\begin{array}{l}\text { CIBSE benchmark for 'good } \\
\text { practice' science lab }\end{array}$ & 110 & 155 & & & \\
\hline $\begin{array}{l}\text { HEEPI (2004) Benchmark } \\
\text { for university bioscience } \\
\text { and medical labs }\end{array}$ & 121 & 250 & & & \\
\hline
\end{tabular}


For comparison, an average British household at the time used approximately $14,000 \mathrm{kWh}$ of gas and $4,000 \mathrm{kWh}$ of electricity per year - roughly $6,000 \mathrm{kWh}$ of gas and $1700 \mathrm{kWh}$ of electricity per capita. Each occupant of buildings $\mathrm{C}$ and $\mathrm{O}$ was therefore using substantially more gas in the workplace than at home, although they were unlikely to spend more than one-fifth of their time there. Electricity use per occupant was even more striking. These figures demonstrate a difficulty with "individualising" environmental impact, when so much of it is associated with collective activities.

\section{The Passive Housing}

In the Swedish passive house case, all apartments were connected to a district heating system for hot water and for supplementary heat on cold winter days. The passive house concept minimises heating needs by creating an air-tight building envelope to reduce heat leakage (Ornetzeder and Rohracher, 2009). The house passively gains the heat from the sun, the tenants themselves, and the equipment installed in the house. In addition, the passive house has mechanical heatrecovery air exchange, so that the fresh air that comes into the house is heated by the outgoing indoor air.

Regarding the energy use of the building envelope, Stångåstaden had installed more heating capacity than is allowed according to traditional passive house specifications. District heating was installed not only for hot water but also for supplementary heating. Because of this, the apartments did not need to use electricity for supplementary indoor heating, which is otherwise common. However, simulations indicated that the energy demand for space heating was only $19.5 \mathrm{kWh} / \mathrm{m}^{2}$ per year and thus meets Swedish passive house specifications that allow a maximum of $25 \mathrm{kWh} / \mathrm{m}^{2}$ per year (Karresand et al., 2009).

Appliances are closely related to electricity consumption, but in a passive house they are also important for achieving a pleasant indoor environment, as explained above. Various household appliances were installed in the apartments. The kitchens were each equipped with a dishwasher, refrigerator, freezer, stove, and ventilation fan. The laundry room was equipped with a washing machine and a tumble dryer; the dryer and the washing machine were classified $\mathrm{B}$ and $\mathrm{A}+$.

The performance of the Lambohov houses in terms of energy use and indoor climate was evaluated, based on a combination of measurements (in 20092010) and simulation. The space heating energy demand varied between $5-25 \mathrm{kWh} /$ $\mathrm{m}^{2}$ over a year, depending on weather conditions (Molin et al, 2011). Temperature levels in the kitchen/living room in the heating season varied typically from 20 to $24^{\circ} \mathrm{C}$ and the temperature was never below $18^{\circ} \mathrm{C}$ in the annual measurements. According to the annual measurements, the tenants preferred a temperature of $\sim 23^{\circ} \mathrm{C}$ in the kitchen/living room.

In summer conditions the kitchen/living room temperature was above $26^{\circ} \mathrm{C}$ for 500 hours, which indicates that the residents could have used more free-cooling through window openings. Looking at the annual heat balance, the apartments had more cooling need than heating need when outdoor temperatures rose above $20^{\circ} \mathrm{C}$.

The measured overall energy performance of the buildings was found to meet the design values in terms of energy use, $21 \mathrm{kWh} / \mathrm{m}^{2}$ which is within the limits for Swedish passive houses as noted above. (For a more thorough discussion on the measurement results, see Molin et al. (2011).) 


\section{Meanings - "Official" and Occupant Perspectives}

Meanings accumulate through engaged practitioners, and we therefore had a particular interest in how the building occupants in Sweden and the UK perceived living and working in these speciallydesigned buildings. We also analysed how the homes and labs had been designed with a set of meanings that were not necessarily the same as those that influenced the daily practices of their occupants.

\section{The Research Labs}

The labs are full of research equipment, with strict health and safety requirements. How do they compare with buildings with the same sort of "meaning"? As Table 1 shows, consumption in all four buildings was well beyond "typical" benchmark figures in use at the time. We do not know to what extent this was due to shortcomings in construction or to the ways in which the buildings were used, including the 24-hour operation. Construction and usage are linked to some extent, given that design is influenced by the building owner's concept of purpose, while the physical components of a building allow some practices while discouraging others.

We do know that the buildings were completed two to four years before the study began, that is, during a period when climate and other environmental considerations were increasingly significant. Yet estimated consumption figures that were available for buildings $\mathrm{C}$ and $\mathrm{O}$ at the design stage show that these buildings were not designed to be in the "typical" range, let alone to represent "good practice". One scientific discourse seems to be at odds with another here: it looks as though it was considered acceptable to break scientifically-derived conventions of good practice in order to conduct scientific enquiry in buildings that would be seen as prestigious. From a practice theory perspective, this is hardly surprising. An account of technical processes and scientific logic is only part of the building performance story, and it needs to be complemented by accounts of routines, meanings, tacit and explicit knowledge, and rules.

The meaning of a 24-hour building immediately seemed questionable to the researchers. All four of the 24-hour buildings normally had very low occupancy between the hours of $7 \mathrm{pm}$ and $7 \mathrm{am}$, and hardly anyone worked there beyond midnight. Occupancy at $8 \mathrm{pm}$ on the nights observed was no more than $8 \%$ of staff in the most highly-occupied of the buildings (C). By $11 \mathrm{pm}$, occupancy was nine individuals in building $\mathrm{B}$ (out of a total of around 325 staff), 8/578 in C, and 1/200 in G. By 3am, these figures had reduced still further, to three, two, and zero respectively. In building $\mathrm{O}$, swipe card data showed very little use of the building beyond 10pm, although there tended to be more at the end of each month, when some staff had to meet reporting deadlines.

Spending an entire night in building B (which had the highest base load electrical demandin relation to overall load-see Figure 1) felt to one of the observers "like spending a night in the hospital, because the building never goes to sleep". The lighting was almost all automated and centrally controlled, and most of it was on all night (Figure 2). Yet this perception of energy wasted at night (based on visible energy use) does not necessarily correlate with what we know of the makeup of the base load. A survey conducted by the university estimated that lighting in the building accounted for approximately $18 \%$ of total electricity use. Less obvious centrally-controlled energy uses, such as air handling, were likely playing a much greater role. However, failure to manage lighting more effectively contributed to a sense of helplessness among staff in building $B$. 


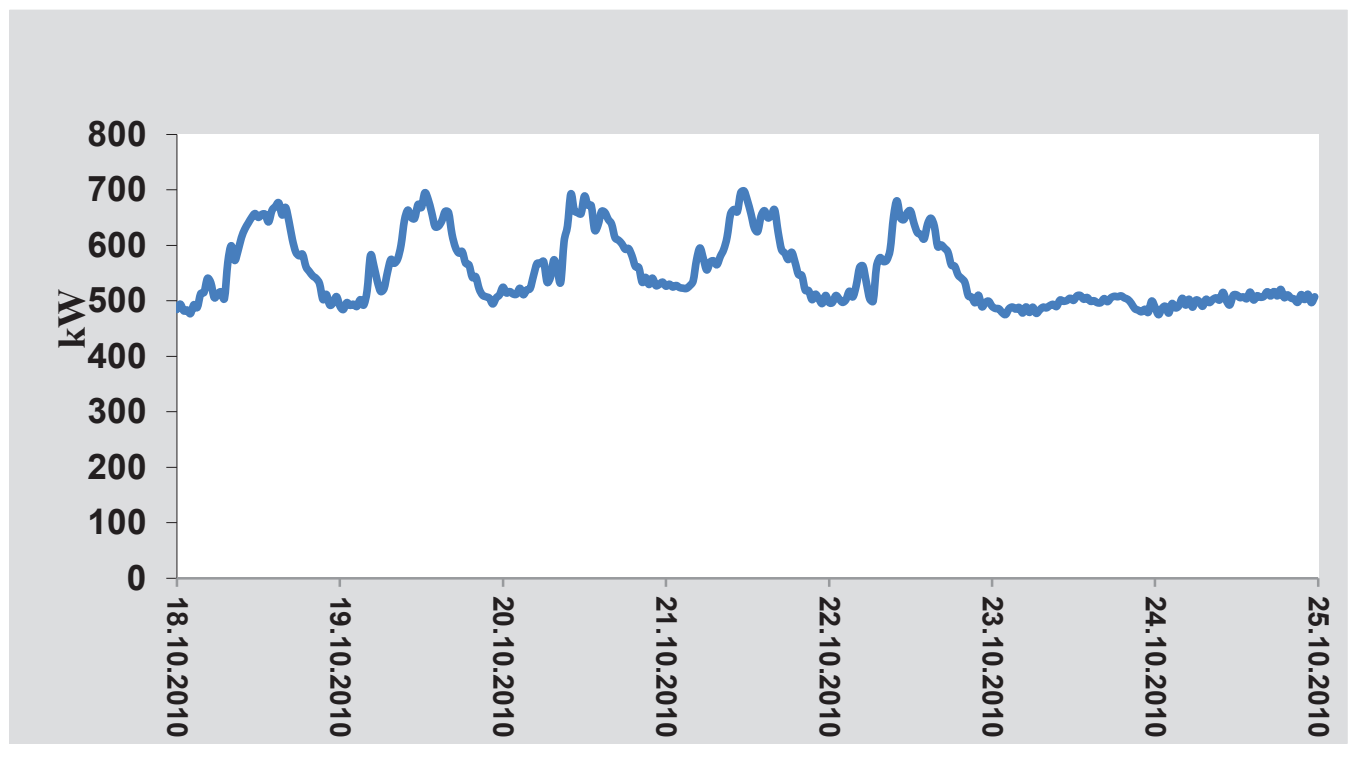

Figure 1. Electricity demand at half-hourly intervals during a week in term time (building B).

Many respondents felt that with so much electricity wasted through lighting, individual attempts to save energy would be somewhat futile. Even if the lighting became more efficient (for example, LED lighting has been installed in building B since this study was conducted), the symbolic message would be the same unless steps were also taken to allow for manual control or more effective automation. The automated systems in buildings $\mathrm{B}$ and $\mathrm{O}$ were particularly complex and difficult to control, and the building managers (BMs) sometimes needed to bring in outside contractors to repair them, which could mean waiting for months. These were clear indications that the promises of "smart" control and automation, attached as they often are to descriptions of prestigious buildings, were not being realised

Figure 2. Night-time lighting in building $\mathrm{B}$. 
either in terms of efficient management or occupant satisfaction.

Interestingly, perceptions of whether energy was being wasted varied depending on the time of day when the occupant was surveyed. Almost three quarters of the 30 daytime occupants surveyed felt that energy was being wasted, in contrast to only two of the eight night time occupants surveyed. This raises the question of what constitutes "waste"? At what level does electrical indoor climate control become "waste" for a researcher working on [what she perceives as] a ground-breaking experiment at $2 \mathrm{am}$ ? And how often is it necessary to work overnight in a lab? From our respondents, the answer seemed to be that this is very rare: even some chemistry experiments can now be monitored from home. While approximately three quarters of the 38 researchers surveyed said that they did work after hours, less than a quarter said that they do so habitually. The majority of "late workers" stated that even when their lab work ran late (after $7 \mathrm{pm}$ ), they did not stay in the building overnight. While the concept of a 24-hour building might sound flexible and empowering, it seemed to be that a "14hour" building might have achieved all that the university intended at the design stage.

There were diverse views on what facilities were needed to perform research to a high standard, and on whether environmental impact is a proper concern for researchers. At one extreme was the view held by one research administrator, that "The main purpose of this group is to do research, not save energy". However, (implicitly) good research outcomes were linked to energy services, and she was not satisfied with the building from that point of view. The building was too complicated, and she complained that

the temperature is never right ..., the air-conditioning doesn't provide a nice environment to work in, the temperature is drastically different in some areas compared to others. Why are we heating and cooling space at the same time!?"

At the other extreme, energy management was seen as being on a par with health and safety considerations, as an integral part of the way in which responsible researchers should operate. Almost all our respondents were pleased that the university was addressing a major sustainability issue.

One researcher made the point that there was a problem with the design process for buildings, claiming that "They want cheap, big, smart-looking buildings, plus they oversize the [heating and ventilation] plant to be on the safe side. Energysaving features aren't the first thing that the university asks for." While there were financial incentives for the university to reduce energy consumption, there was far more of an imperative to bring in fresh research funding than to reduce costs. A prestigious building was intended to help this process, attracting researchers by offering cutting-edge facilities. One department reported that putting a picture of their new building on their website led to a $50 \%$ increase in applications to study there. We see, again, how meanings affect design and day-to-day practices, and how a building can be configured using one set of meanings in such a way that it is difficult to operationalise another set, those related to reducing environmental impact.

\section{The Passive Housing}

In Sweden the municipally owned housing company $\mathrm{AB}$ Stångåstaden built the passive apartments as a test project, wanting to know whether the "market is ready for passive houses" (interview, project manager). Stångåstaden representatives said that tenants in the passive apartments need to be energy conscious, willing to learn 
how the heating system works and willing to adapt to the specific functions of a passive apartment. A project manager for example said:

"As a tenant, you need to be aware that if the outdoor temperature is minus $30^{\circ} \mathrm{C}$ one morning, then it might not be possible to have an indoor temperature of $20^{\circ} \mathrm{C} . "$

The Stångåstaden representatives all believed that extra information was needed when introducing tenants to the passive apartments. Extra information was prepared and folders on the passive house concept were distributed when the apartments were shown. When the tenants moved in, the project manager made a personal visit and informed them about the heating system and the passive house concept. He claimed that the heating system was easy to handle: the tenant just turns a knob to the preferred temperature (interview, project manager).

All tenants mentioned similar motives for choosing their apartment. Everything is new: living space, design of the apartment, low running costs, good communications, schools, day care etc. Most of the tenants did not specifically look for a passive house but got the information through their contacts with Stångåstaden. One of the households explained:

" We looked at Stångåstaden's website to see where there were apartments available and we found these in Lambohov. When we then talked with Seller B she explained that the apartments available were of both conventional and of passive house standard. So we didn't actively search for passive houses, it was more of a coincidence."
Five of the households did however emphasize environmental reasons as important incentives for the decision to move into the apartment. One expressed this in connection with an instinct to be environmentally-friendly, saying that "It gives you a good gut feeling to live in a passive house". One household wanted to try out "new technology" as they put it, to see if it actually worked, and they wished to live in a new "climate smart" building rather than an old less energy efficient house. Besides environmental incentives, several mentioned financial incentives and hoped that a passive apartment would also give a lower energy bill. The tenants said that they probably would need to learn how to live in their new apartment, and that they were prepared to adapt their behavior. For example, they would keep the front door shut and wear slippers.

The meanings assigned to passive housing were therefore not dissimilar between the landlord and tenants, and there was a realistic acceptance that some adaptation and learning were required. The technology alone would not achieve everything in terms of comfort and energy saving.

\section{Knowledge of how to Produce Thermal Comfort and Operate Appliances}

In this section we will focus on the households' and building managers' knowledge on how to produce thermal comfort. The knowledge category includes rules of how to do things as well as technical knowledge.

\section{The Research Labs}

The building managers (BMs) played a crucial role in maintaining these technologyintensive buildings and had unique access to the building management systems. All were 
highly qualified, and three had previously worked as researchers themselves. It took time (about two years) for the BMs to become fully familiar with their buildings, and some major adjustments were made during that period to limit consumption.

Energy management was only one of their many responsibilities, though. Their main task was maintaining a safe, pleasant working environment for researchers and other staff. In practice, this often meant tweaking the management systems in order to keep most of the occupants happy for most of the time - satisficing rather than optimising (Leaman and Bordass, 2001). This was likely to be far more complex than maintaining a pleasant environment in a home, as there were so many people to be kept content. One BM had the challenge of managing a building for six departments, each with its own administration and requirements.

Building managers varied in the extent to which they encouraged users to conserve energy. One showed how a safety-based induction programme for new researchers, backed up by random checks on the operation of fume cupboards, could help to contain demand for electricity. He was strongly backed by a head of department who was keen to reduce the environmental impact of the building. It was in this lab, building $\mathrm{C}$, that it was easiest to see how a number of apparently small changes in routine, initiated mostly by the BM, had added up to a significant reduction in energy demand over a period of two years.

The extent to which control, decisionmaking and knowledge were shared emerged as a significant factor in building management. For example, three of the four BMs were not able to make decisions on some aspects of their facilities, notably in operating the HVAC systems, which were contracted out. We found that the BMs often worked in relative isolation from their peers; they supported the idea of setting up a forum in which they could learn from each other.

Energy was not necessarily discussed at the senior management level for each building, and many respondents stressed the importance of leadership. They commented that when heads of department and university decision-making bodies stress the significance of energy, it becomes more likely that researchers will pay attention, and that BMs will have more authority to implement changes in practice.

\section{The Passive Housing}

In the passive house case, the tenants are also managers of the systems. A passive house has a technology construction that requires action from the tenants. Usually the tenants' activities and appliances are described as part of the building's heating system, and the information given to the tenants on arrival gives guidance only on how to keep warm. But this does not help the tenant in deciding what to do about cooling in summer. In Sweden, residential buildings usually do not have air conditioning. In general, the tenants thought that their apartments became too hot on sunny days, though not unbearably so. They also said that the heat remained in the building, making it difficult to cool the apartment down. One had measured an indoor temperature of $33^{\circ} \mathrm{C}$ and had discussed installing an air conditioner.

The householders said they knew how to regulate the temperature, but one household never touched the thermostat because they said they needed more specific information on how to adjust it. Three claimed that they knew how to adjust the thermostat but that it did not matter, because there was nothing to be done if they wanted to cool off the apartment.

During the winter four of the households complained about problems with temperature differences inside the 
apartment, as they could not adjust the temperature individually in each room (which you normally can if you have radiators in the rooms). The bathroom and toilet were described as either too cold or too warm, and all the households had the toilet door on the second floor open all the time, either as a way to keep the toilet from becoming 'ice cold' or to allow the 'heat' from the toilet to get to the rest of the apartment. One household was planning to buy a fan for the first floor to blow the heat down to the ground floor. These conflicting perceptions baffled the researcher, who found the toilets in all the homes to be about the same temperature.

Another household said that, compared with apartments they had lived in before, this was better because it was the first time they knew how to adjust the indoor temperature themselves; heating systems in earlier apartments had been like 'black boxes' to them.

Some of the tenants also become experts and learnt how to manage the technical systems in the house. They complained of dry air during the summer and had experienced technical problems with the ventilation system. One was not especially upset, saying that they could accept some minor problems like this in the beginning. But another system stopped working when the winter was at its coldest, and the occupiers thought that the biggest problem was that no one understood their system:

"So even though we report the problems to the on-call person, they don't know much about the system. No one does. No one knows how these systems are connected and work or how you are supposed to adjust the settings. So in the end, I and my partner needed to learn more about the system ourselves, look at the Internet and so on."
This household became technically expert and learned how to handle the system. Another household experienced several problems with the heat exchanger and contacted the housing company several times, but never got any help. They did not accept the explanation that the extremely cold weather had contributed to the problem and eventually learned how to repair the system themselves. A third household was worried that the system might stop working at night and that their kids would "wake up to six degrees in the morning". They lacked technical knowledge and felt that they had changed their routines drastically as they dressed the children at night and used extra blankets.

\section{Changing Routines for Improved Energy Management and Comfort}

Routines are bodily and mental activities carried out by practitioners and include habits and know-how. Changing routines for the use of appliances and equipment are often mentioned as important for improved energy efficiency, and this was an issue that appeared also in our case studies.

\section{The Research Labs}

In one of the labs, the BM reported that $£ 35,000$ a year had been saved by switching off four $35 \mathrm{~kW}$ autoclaves overnight and at weekends. He had had to persuade researchers that they would still be able to carry out sterilisation when they wanted, without more than short periods of waiting for the equipment to be ready. This had involved occasional adjustments to their routines, but perhaps more significant changes in their ways of thinking about the task of sterilisation.

Many respondents felt that there could be a much better job of turning off unused equipment, which of course raised the issue of responsibility. It was possible to find work 
areas where all of the computer monitors, desk lamps and lab lighting had been turned off at night - that is, everything that was under the researchers' control. But this was often not the case. A researcher commented that "lab machines are left on because you don't know late at night whether someone else will want to use it, and if it's switched off it takes ages to switch back on." Many items were left on around the clock largely because someone might want to use them an indication of conflict between individual and group wishes and priorities.

\section{The Passive Housing}

The householders thought it was difficult to find routines to lower indoor temperature in the summer. Those who had awnings used them, while the others only had window blinds to block out the sun. Three households said that they kept their windows open when they were at home, even though they were told not to. One household told us that:

"But we have the window open and we keep it open at night. But they say that you shouldn't do that in a passive house. You should not air out the house, but only open up [i.e. the windows] when it is as hot outside as inside."

The householders had especially been told to be careful with opening the windows. But that was because they moved in during winter time and obviously thought that this information also applied to the summer. The householders understood that they just had to stand the heat, and recalled that Swedish summers are not that long.

All households in the passive apartments discussed ways they used to keep the indoor temperature at a comfortable level in the winter. Common practices were to leave a lamp on at night, light a candle, turn on the washing machine and tumble dryer, turn on a light, and turn on the TV. One household said they preferred to put on cardigans and slippers and avoided using appliances to heat the apartment.

One household had tried raising the thermostat to $22^{\circ} \mathrm{C}$, in order to have an indoor temperature of $20^{\circ} \mathrm{C}$. This, however, resulted in extra expense for the family when the supplementary district heating system turned on. Instead, they used the $\mathrm{TV}$, washing machine and dryer to heat the apartment, but did not discuss the fact that this also resulted in increased costs for the family. They found that it was more difficult to achieve an even temperature in the winter than in the summer, because in the summer they could at least air out the apartment by opening the windows. In the winter, they had no way to increase the temperature quickly.

One household had started to open the windows apartment routinesly, even in the winter:

\footnotetext{
"We open up [the windows], because we have noticed that in this air-tight building the air is different. If we are both taking a shower in the morning, then it is like we need an extra fan because the air becomes moist and sticky. Then we need to open the windows in both the bathroom and bedroom."
}

When it was coldest, this household went home to the wife's mother. They also baked a lot, used many candles, and let the child sleep in their bed to keep her warm. Despite these efforts, they thought that the child had become unwell because of the cold apartment.

\section{Discussion}

There are clearly differences between the case studies in terms of construction standards, expectations, climate, occupancy, and usage patterns. There are also similarities. Both sets of buildings 
were designed to be "different", and to be prestigious "forerunner" buildings using new technologies. Both were tenanted rather than owner-occupied, and the occupants of both lacked control over the whole system, needing backup from either the housing association or the university. Both also required some expert knowledge in order to achieve comfort and carry out activities.

In both cases we have seen that the buildings are designed in ways that influence the practices of the residents. Table 2 summarises some characteristics of each type of building, in categories recognised in the variant of practice theory we have referred to earlier (Gram-Hanssen, 2010).

The table indicates the interrelatedness of everyday living and working practices with the practices of designing and constructing a building and setting it to work. For example, once a building designer has made the conceptual leap to believing it is possible to be comfortable in a home without traditional heating, a new set of practices begins to be adopted by builders and residents, and by other designers. Builders are guided in their practices by user expectations as well as by architects' designs; users have practices (such as nighttime working, control of lighting, tactical

Table 2. Passive housing and research labs in relation to practices.

\begin{tabular}{|c|c|c|}
\hline & Passive housing & 24-hour research lab \\
\hline Technology & $\begin{array}{l}\text { The passive house itself, with } \\
\text { district heating available as back-up; } \\
\text { appliances that can be used for "waste" } \\
\text { heat as well as for specific purposes }\end{array}$ & $\begin{array}{l}\text { The lab building is a sort of machine, } \\
\text { controlled primarily by the building } \\
\text { manager; HVAC and research } \\
\text { equipment are operated for the } \\
\text { convenience of many researchers at } \\
\text { different times of day. }\end{array}$ \\
\hline Meanings & $\begin{array}{l}\text { A house does not have to have a } \\
\text { customary heating system; a washing } \\
\text { machine becomes a source of ambient } \\
\text { heat; a passive house is heated by } \\
\text { active people - and can be cooled to } \\
\text { some extent, by disobeying the normal } \\
\text { rules and opening windows in hot } \\
\text { weather. }\end{array}$ & $\begin{array}{l}\text { The lab is a site for complex, expensive } \\
\text { research work; can also attract new } \\
\text { researchers. A researcher is entitled to } \\
\text { workspace and functioning equipment, } \\
\text { around the clock. A prestigious } \\
\text { building has fully-automated climate } \\
\text { and lighting control. There may now be } \\
\text { reputational risk from a building that is } \\
\text { seen as wasteful of resources. }\end{array}$ \\
\hline Knowledge & $\begin{array}{l}\text { How to produce and maintain thermal } \\
\text { comfort; how to gain access to advice } \\
\text { and assistance }\end{array}$ & $\begin{array}{l}\text { How to produce thermal comfort and } \\
\text { good working conditions for many } \\
\text { people at the same time (BM). How } \\
\text { to operate research equipment. When } \\
\text { and how to apply restrictions on } \\
\text { working times, practices, equipment } \\
\text { or building services }\end{array}$ \\
\hline Routines & $\begin{array}{l}\text { Timing the use of appliances to } \\
\text { coincide with need for extra warmth; } \\
\text { altering clothing } \\
\text { Accepting limitations to and } \\
\text { shortcomings in thermal comfort }\end{array}$ & $\begin{array}{l}\text { Timing and nature of work; use of } \\
\text { equipment; consideration of energy } \\
\text { issues at departmental meetings; } \\
\text { maintenance of health and safety }\end{array}$ \\
\hline
\end{tabular}


use of appliances for comfort) opened up or closed down by the practices involved in building development.

The studies indicate that building energy management involves factors that are both physical (building fabric and equipment) and social (the rules by which these operate). We have seen how the people in charge of controlling a home or a large workplace after some time work out ways of "satisficing", achieving "good enough" living or working conditions for the occupants. This can be interpreted as a period of learning how to manage hardware and software, during which the limits of the building design can be tested. It is interesting that in both case studies, this period lasted longer than a year. Sometimes occupants discover that the recommended building technology framings can be ignored or subverted. For example, it is not only possible but good to open the windows of a passive house on a Swedish summer evening in order to cool the house. Or it is possible to make working conditions more pleasant in an over-cooled workplace by smuggling in an electric fan heater.

Low energy buildings are designed with particular characteristics and these do not emerge from nowhere, but from the aspirations and norms of people in particular social groupings. Practice theory, by taking meanings, knowledge and routines into account, brings these aspirations and norms into the story.

These case studies have shown the significance of both individuals and organisations in developing energy efficient practices: Stångåstaden housing association and its staff, architects, and the people who approve designs for new buildings; managers and their concerns for the viability and reputation of their organisations. The studies also show some possibilities for promoting more sustainable energy related practices through learning from experience, and they show how changed practices can be carried out by many actors: householders, building managers, technicians and researchers and energy advisers, in addition to managers and designers. Practice theory, especially as it has been developed in relation to sociology by researchers such as Schatzki and Shove, allows options for change to be identified and discussed but tends to stop short of dealing explicitly with organisational and relational issues. These form an optional further step, and an essential one in terms of learning. In the short term, the case studies show how 'single loop' learning (Schon, 1983 ) is taking place, as people discover how to manage their buildings more effectively or to carry out particular practices. In the longer term, they show how critical it is that post-occupancy evaluation feeds back to the people responsible for the design of new buildings (Leaman et al., 2010) - a form of 'double loop' learning. An important development for the socio-cultural branch of practice theory is to connect it to different aspects of learning (Hasu 2001; Gherardi 2006), and to try to internalise the study of knowledge/learning, meaning and routines into technology design and operation, extending the boundaries of the traditional systematic approach. The incorporation of social science modules in engineering courses is an example of this; so is postoccupancy evaluation.

\section{Summary and Conclusions}

Concepts from practice theory technologies, routines, knowledge, and meaning - have been applied to an account of how people have been learning how to interrelate with technology in new passive houses and new purpose-built research buildings. We have also aimed to develop sociological practice theory through a multisite analysis of practices relating to energy infrastructures and the built environment. 
The Swedish residential case study showed how a combination of technologies and satisficing became the 'new normal' for residents, after a process of trying to make those technologies work for them, and adapting their own practices. The design of the building with its technology mattered, but the main project of a liveable, low-impact new building was on a fairly manageable scale once people had some time to work out meanings, build knowledge and develop new routines. The goals were not entirely achieved, but seemed within reach, given more attention to knowledgebuilding and practices.

By contrast, the research lab study showed limited room for manoeuvre in very highly technical buildings, once the design decisions had been made. Some occupant practices were able to change, but control of the indoor climate and much of the lighting climate was centralised, automated and highly complex, while energy management was not seen as a priority by many of those responsible for overseeing the research carried out in the buildings. Although so much was at stake in these buildings in terms of reputation, finance and environmental impact, there was little sign of a feedback loop from which architects, design committees and the higher education sector could learn for the future. The findings from this case study indicate why it can be difficult to reduce energy use without changes to the ways in which scientific research is practised. They illustrate the configuration of unsustainable technologies and practices that can occur at the design stage, and the way in which the significance of the 'core business' of the labs can overwhelm energy considerations.

The contrast between 'passive' (lowenergy-intensity) and 'active' (high energyintensity) buildings is striking. Learning for sustainability seems to be facilitated by the former farmore than by thelatter. Specialised buildings need specialised design, but the process tends to leave out consideration of meanings (what does scientific activity mean in the 21st century? what is comfort at work?); routines (how much provision for 24-hour work is really needed, and how can it be provided most effectively? how much control should be delegated to teams and individuals?); and knowledge (who needs to understand how to construct, maintain and operate a building in an ecologically sound way, and how can they best be trained?)

The analysis shows that practice theory offers a means of interpreting what happens in the course of designing, constructing and inhabiting buildings that are intended for residential or for highly-specialised uses. It helps to show why the environmental outcomes for a relatively simple 'passive building (ultra-low-fuel, with active occupants) are not far from expectations: the building is designed for both comfort and 'environmental' purposes, the meaning is fairly uncontroversial, and the adaptation required from occupants is modest but achievable. It also helps to show why the environmental outcomes for very complex 'active' buildings (high-fuel, passive occupants) have been so disappointing: here, the design is tight (for very specific purposes), but the meanings are more contested among many occupants, and even the building manager may not be able to make many significant adaptations. However, this application of a practice theory perspective in the field of energy studies, with an emphasis on active learning, illustrates how there is still room to extend the vocabulary and scope of practice theory.

\section{Acknowledgements}

The case study in Sweden was funded by the Swedish Energy Agency. The Midnight Oil project was funded by the Higher Education Funding Council for England's Leadership, Governance and Management Fund, and much of the research for Phase One of the 
project was carried out by Dana Cartwright and Jennifer Wilson. The Department of Thematic Studies at the University of Linköping offered a visiting lectureship to Sarah Darby in 2011-12, which made it possible to write this paper, and we thank colleagues in Linköping and Oxford who made constructive suggestions and criticisms. Our thanks go to the reviewers, too, for their many helpful comments.

\section{References}

Bourdieu, P. (1977) Outline of a theory of practice (Cambridge: Cambridge University Press).

Darby, S. (2006) 'Social learning and public policy: lessons from an energy-conscious village', Energy Policy, 34(17): 2929-2940.

Darby S., Cartwright, D. \& J. Wilson (2010) Midnight Oil phase 1 report. Unpublished report for the University of Oxford Estates Directorate, available from Sarah Darby at the Environmental Change Institute, University of Oxford.

EU Directive 2006/32/EC of the European Parliament and of the Council of 5 April 2006 on energy end-use efficiency and energy services and repealing Council Directive 93/76/EEC. Official Journal of the European Union, Brussels. http:// eur-lex.europa.eu/legal-content/EN/ TXT/PDF/?uri=CELEX:32006L0032\&fro $\mathrm{m}=\mathrm{en}$.

Falzon, M-A (2009) 'Introduction. Multisited Ethnography: Theory, Praxis and Locality in Contemporary Research' in M-A Falzon (ed), Multi-Sited Ethnography: Theory, Praxis and Locality in Contemporary Research (London: Ashgate Publishing): 1-24.

Fawcett, T. (2005) Energy use and carbon emissions from the higher education sector. UKERC, London. UKERC Working Paper. http://s3.amazonaws. com/zanran_storage/www.ukerc.ac.uk/ ContentPages/18589226.pdf
Gherardi, S. (2006) Organizational Knowledge: The Texture of Workplace Learning (Massachusetts: Blackwell).

Giddens, A. (1984) The Constitution of Society. Outline of the Theory of Structuration (Cambridge: Polity Press).

Gieryn, T. F. (2002) 'What buildings do', Theory and Society 31(1): 35-74.

Gill, Z. M., Tierney, M. J., Pegg, I. M. \& N. Allan (2010) 'Low-energy dwellings: the contribution of behaviours to actual performance, Building Research \& Information 38(5): 491-508.

Glad, W. (2012) 'Housing renovation and energy systems: the need for social learning, Building Research \& Information 40(3):274-289.

Gram-Hanssen, K. (2010) 'Residential heat comfort practices: understanding users', Building Research and Information 38(2): 175-186.

Gram-Hanssen, K. (2011) 'Understanding change and continuity in residential energy consumption', Journal of Consumer Culture, 11 (1): 61-78.

Hasu, M. (2001) Critical Transition from Developers to Users. Activity-Theoretical Studies of Interaction and Learning in the Innovation Process. (Dissertation: University of Helsinki).

HEEPI (2004) Results of the HEEPI HE Building Energy Benchmarking Initiative 2003-4. Higher Education Environmental Performance Improvement project.

Hine, C. (2007) Multi-sited ethnography as a middle range methodology for contemporary STS, Science, Technology and Human Values 32, 652-671.

Jensen, J.O. \& K. Gram-Hanssen (2008) 'Ecological modernisation of sustainable buildings: a Danish perspective', Building Research and Understanding 36(2): 146158.

Karresand, H., Molin, A., Persson, J. \& M. Åberg (2009) 'How passive are your activities? An interdisciplinary comparative energy analysis of passive 
and conventional houses in Linköping, Working paper no 42, Program Energisystem, Linköping.

Leaman, A. \& B. Bordass (2001) 'Assessing building performance in use 4: the Probe occupant surveys and their implications', Building Research and Information 29(20): 129-143.

Leaman, A., Stevenson, F. \& B. Bordass (2010) 'Building evaluation: practice and principles', Building Research and Information 38(5): 564 - 577.

Löfström, E. \& J. Palm (2010) 'On the invisible socio-technical systems - the great unknown', International Journal of Power and Energy Systems 30(3): 176182.

Marcus, G.E (1995) 'Ethnography in/of the World System: The emergence of MultiSited Ethnography' Annual Review of Anthropology, 24: 95-117.

Moezzi, M. \& L. Lutzenhiser (2010) What's missing in theories of the residential energy user? Proceedings, American Council for an Energy-Efficient Economy summer study on energy efficiency in buildings, 7-207 -221.

Molin, A., Rohdin, P. \& B. Moshfegh (2011) 'Investigation of energy performance of newly built low-energy buildings in Sweden', Energy and Buildings 43(10): 2822-2831.

Ornetzeder, M. \& H. Rohracher (2009) 'Passive houses in Austria: the role of intermediary organisations for the successful transformation of sociotechnical system,' Proceedings, ECEEE Summer Study, Paper 7175: 1531-1540.

Palm, J. (2011) 'Energy efficiency in households. Policy, Implementation and everyday activities' (New York: Nova Science Publishers, Inc.).

Palm, J. \& K. Ellegård (2011) 'Visualizing energy consumption activities as a tool for developing effective policy', International Journal of Consumer Studies, 35(2): 171179.
Pett, J. \& P. Guertler (2004) 'User behaviour in energy efficient homes' Phase 2 report, Association for the Conservation of Energy, London.

Pollock, N \& R. Williams (2010) E-infrastructures: how do we know and understand them? Strategic ethnography and the biography of artefacts. Computer Supported Cooperative Work19, 521-556. Reckwitz, A. (2002) 'Toward a Theory of Social Practices: A Development in Culturalist Theorizing' European Journal of Social Theory 5(2): 243-63.

Rohracher, H. (2006) The Mutual Shaping of Design and Use: Innovations for Sustainable Buildings as a Process of Social Learning (Vienna: Profil).

Røpke, I. (2009) 'Theories of practice: new inspiration for ecological economic studies on consumption', Ecological Economics 68(10): 2490-2497.

Schatzki, T. R. (1996) Social Practices: a Wittgensteinian approach to human activity and the social (Cambridge: Cambridge University Press).

Schon, D.A(1983) The Reflective Practitioner (Basic Books: New York).

Shove, E. (2003) Comfort, cleanliness and convenience (Oxford: Berg).

Shove, E., Watson, M., Hand, M. \& J. Ingram (2007) The Design of Everyday Life (Oxford: Berg).

Spaargaren, G. (2003) Sustainable consumption: a theoretical and environmental policy perspective, Society and Natural Resources 16(8): 687-701.

Stagl, S. (2006) 'Multicritera evaluation and public participation: the case of UK energy policy', Land use policy 23(1): 5362.

Steemers, K. \& G.Y. Yun (2009) 'Household energy consumption: a study of the role of occupants, Building Research \& Information 37(5-6): 625-637. 
Stewart, J. \& R. Williams (2005) 'The wrong trousers? Beyond the design fallacy: Social learning and the user, reprinted, in D. Howcroft et al (eds), Critical IT Handbook (Cheltenham, Edward Elgar): 195-221.

Sørensen, K.H. (1996) ‘Learning technology, constructing culture: socio-technical change as social learning' STS Working Paper no. 18/96, Centre for Technology and Society, University of Trondheim.

Vergragt, P.J \& H. Szejnwald Brown (2006) 'Sustainable mobility: from technological innovation to societal learning', Journal of Cleaner Production 15(11-12): 11041115.

Wilhite, H. (2008) New thinking on the agentive relationship between end-use technologies and energy-using practices. Energy Efficiency 1 (1), 121-130

Wilson, C., and Dowlatabadi, H. (2007) Models of decision making and residential energy use. Annual Review of Environment and Resources 32, 169-203.
Jenny Palm

Linköping University

Department of Thematic Studies

- Technology and Social Change

58183 Linköping

Sweden

jenny.palm@liu.se

Sarah J Darby

Environmental Change Institute

Oxford University

South Parks Road

OXFORD OX1 3QY

sarah.darby@ouce.ox.ac.uk

\section{Notes}

1 For example, see http://www.iea.org/ topics/energyefficiency/

2 Energy figures were calculated from utility bills for the financial year August 2009-July 2010.

3 Chartered Institution of Buildings Services Engineers 